\title{
SIMULATION MODEL OF ELECTRIC VEHICLE TO GRID TECHNOLOGY FOR BALANCING LOADS AND FREQUENCY REGULATIONS
}

\author{
Dr. C V Mohan \\ Assoc. Professor \\ EEE Department \\ Sir MVIT., Bangalore
}

\begin{abstract}
The Electric Vehicle to Grid Technology is the emerging and promising field for the future of sustainability, as it offers balancing of the grid systems using a source of energy from the Electric Vehicles. This paper presents a bi-directional flow of energy between a fleet of Electric Vehicles and the grid. This technology proposes a method of balancing of loads and frequency regulation by integrating the Electric Vehicle with the renewable energy sources such as solar array and wind farm and the diesel power plant is used as the base plant. It further discusses about the new trend of using Electric Vehicles for balancing of grid systems and enhanced use of sustainable energy and benefits of owning an Electric vehicle thus contributing to the economic benefits in the business models in energy industry. The simulation for 24hrs is carried out and the resultant graph pattern based on the irradiance on the solar panel and the wind speed is obtained and the state of charge of the Electric Vehicle batteries is further observed.
\end{abstract}

Key Terms-- Electric Vehicle, frequency regulation, grid technology, load balancing, renewable energy.

\section{INTRODUCTION}

Electrical energy is the most essential part of our life. Electricity can be generated using conventional and nonconventional resources in the present days. Without electricity lives on this planet is unimaginable. For all our tasks to be completed these days electricity is the main requirement. Energy production and distribution are continuously growing with the development of increasing volumes of renewable energy sources, which are constantly pushing the energy efficiency limits. With stringent legislation, environmental awareness and rising gasoline prices, Electric Vehicles (EVs) are presented as a promising green solution to reduce emissions and fuel consumption for the automotive industry. EVs can also be used as versatile loads in smart grid applications such as electricity sources, energy storage systems or charging Liu Chunhua et.al (2013).

To effectively utilize the full potential of EVs as a flexible grid-connected energy tool, EVs can be operated not only to charge, but also to transfer energy back to the grid at appropriate times. This is called as Electric Vehicle to Grid Technology. It is the bi-directional flow of electric

\author{
Deepthi R, Akshay H, Vineeth G D, Srikanth S, \\ Student \\ EEE Department \\ Sir MVIT. Bangalore
}

energy between the vehicle and the electrical grid. The Electric Vehicle to Grid Technology incorporates the ability to convert the vehicle into a Distributed Energy Resource (DER) that has the potential of integrating with micro grids. In addition to the low carbon future that Electric Vehicle to Grid Technology supports, it also introduces the consumer's prospect of financial incentives, by offering the grid frequency regulation and load balancing. By participating in balancing of loads and frequency regulation, the system is able to perform day to day scheduling charging/discharging to reduce the cost of ownership of the EVs Amamra Sid-Ali et.al (2019). The existing Electric Vehicle to Grid Technology principles include the incorporation of intermittent renewable energy into the grid, reducing peak load, optimizing charging and regulating participating power. In this paper we will further discuss about how to the balancing of load and frequency regulation is done by integration of renewable energy and Electric Vehicles.

\section{METHODOLOGY}

- The grid is divided into the following four parts: A diesel generator which acts as a $15 \mathrm{MW}$ base power generator; an 8MW photovoltaic farm which is combined with a $4.5 \mathrm{MW}$ wind farm is used to produce renewable energy; an Electric vehicle to Grid Technology system installed next to the last part of the system which is the load of the grid as shown in Fig.1

- The diesel generator serves to balance the power consumed and the power generated. Grid frequency deviation can be determined by looking at the rotor speed of the synchronous machine's. When the demand is more, then the load on the diesel generator is increased to meet the demand.

- The energy produced by the PV farm depends on three factors: the area covered by the PV farm, the efficiency of solar panels and the data based on the irradiance.

- The wind farm produces electric power, this power follows a wind liner relationship. The wind farm produces nominal power when it reaches the nominal velocity. When the wind speed reaches the average wind value, the wind farm trips from the grid before the wind returns to its nominal value.

- The voltage from the generation units is stepped up 


\section{International Journal of Engineering Applied Sciences and Technology, 2020 \\ Vol. 5, Issue 4, ISSN No. 2455-2143, Pages 203-208 \\ Published Online August 2020 in IJEAST (http://www.ijeast.com)}

to $25 \mathrm{kV}$ using a step up transformer and further stepped down to $500 \mathrm{~V}$.

- It is further disturbed to the load and the Electric Vehicle.

- The load consists of residential loads and an asynchronous machine representing an inductive industrial load on the micro grid.

- The residential load follows a profile of consumption within a given power factor.

- The asynchronous machine has a square relation between the rotor speed and the mechanical torque.

- The status of the parameters is stored in the smart grid which helps in monitoring, whenever the demand is increased on the load side the Electric Vehicle receives a signal from the smart grid and helps in the balancing of load and frequency regulation on the grid side.

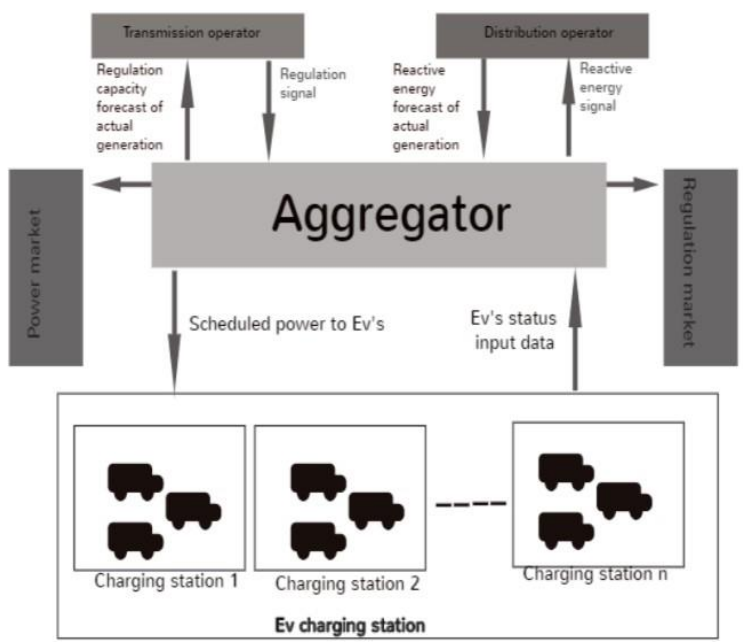

Fig.1 Block Diagram

III. RESULT

The simulation lasts for $24 \mathrm{hrs}$. The solar intensity falling on the panel follows a normal pattern where it reaches the maximum intensity during the midday. During the day the wind speed varies greatly and it has several peaks and lows. The residential load follows a characteristic pattern similar to that of the regular household usage. During the day, the consumption is low and it increases to a peak during the evening, and gradually decreases during the night. Each surge in load last for 3-5 minutes with slight variations in the frequency and it is restored back.

\section{A. Generation of Power}

\section{1) Generation parameters of Diesel Power Plant}

Fig. 2 represents a graph of the voltage level generated by the diesel power plant versus time whereas Fig. 3 represents the current generation based on the regulation control. The power developed by the base plant is represented in Fig.4, Fig.5 and Fig.6 respectively.

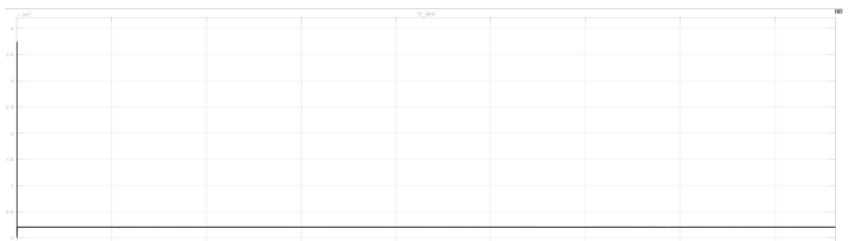

Fig. 2 Voltage Graph (time vs voltage)

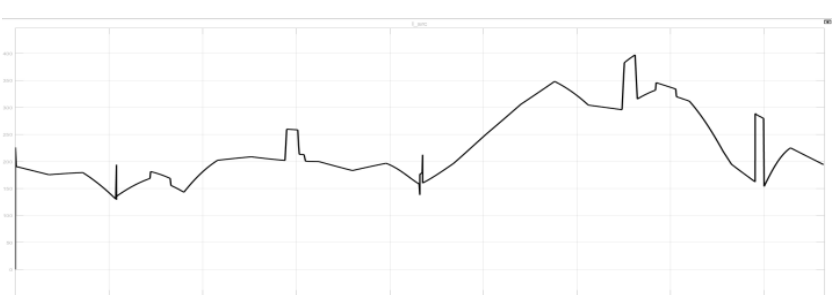

Fig. 3 Current Graph (time vs current)

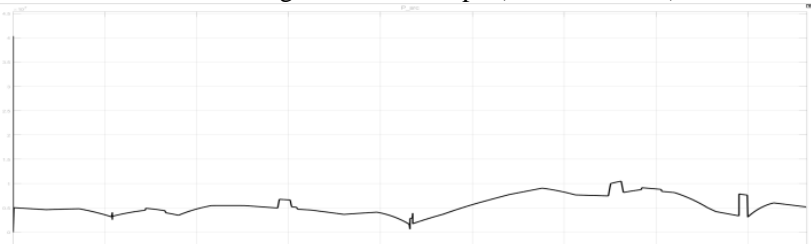

Fig. 4 Active Power (time vs active power)

Fig. 5 Reactive Power (time vs reactive power)

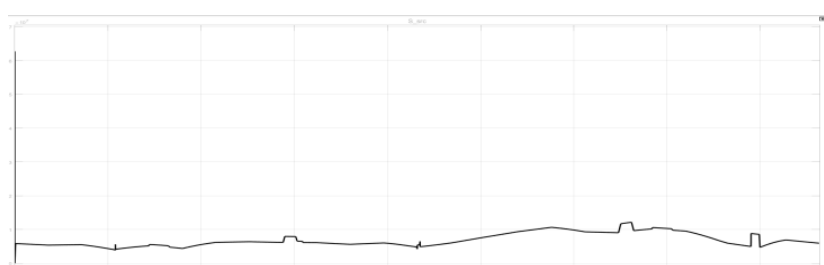

Fig. 6 Apparent Power (time vs apparent power)

\section{1) Generation Parameters of Wind farm}

The voltage generated by the wind farm is shown in Fig.7. Fig. 8 represents the current produced as per the speed of wind (see wind profile for it) and above nominal cutoff at certain circumstances where its 0 . The power generated is as shown in Fig. 9, Fig.10 and Fig. 11 
Fig. 7 Voltage Graph (time vs voltage)

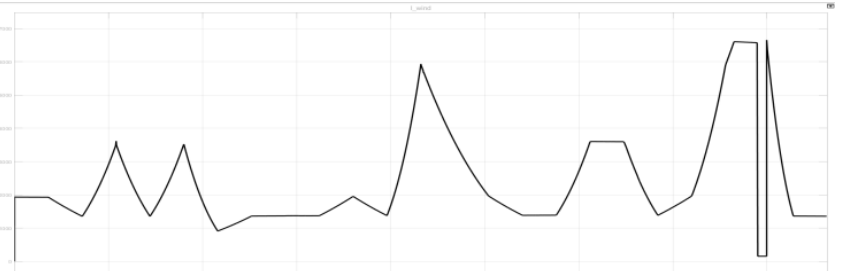

Fig. 8 Current Graph (time vs current)

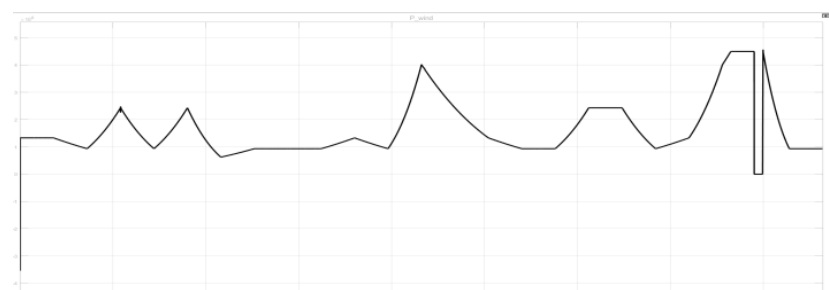

Fig. 9 Active Power (time vs active power)

Fig. 10 Reactive Power (time vs reactine power)

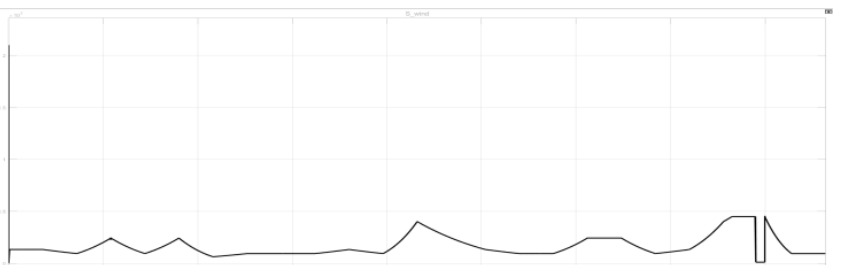

Fig.11 Apparent Power (time vs reactive power)

1) Generation Paramters of Solar Array

The voltage, current and power developed by the solar panels is based on irradiation and shading is as shown in Fig.12, Fig.13, Fig.14, Fig.15 and Fig.16.
Fig. 12 Voltage Graph (time vs voltage)
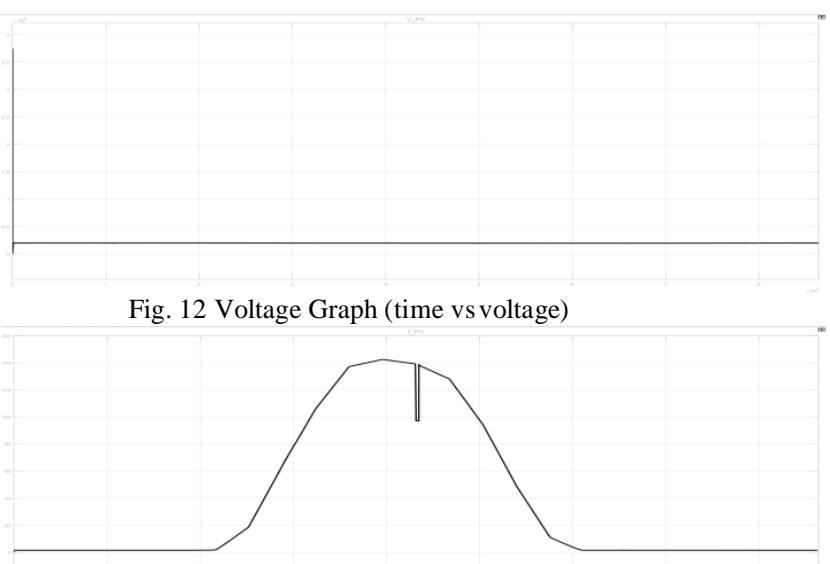

Fig. 13 Current Graph (time vs current)

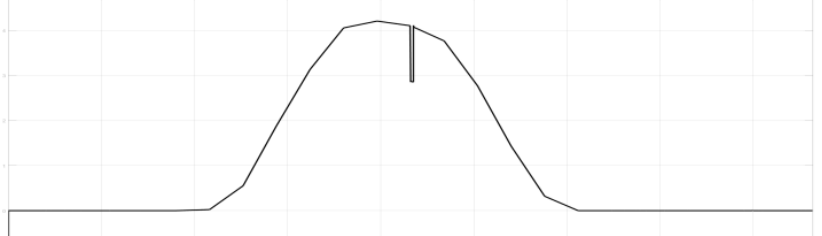

Fig. 14 Active Power (time vs active power)

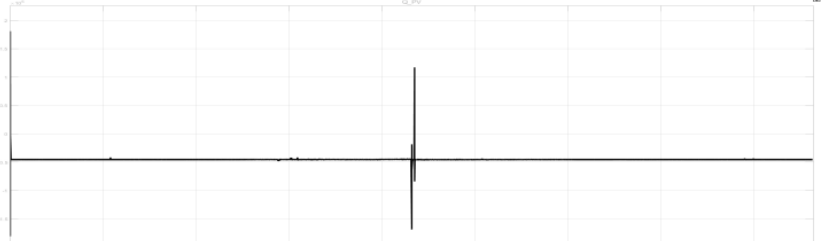

Fig. 15 Reactive Power (time vs reactine power)

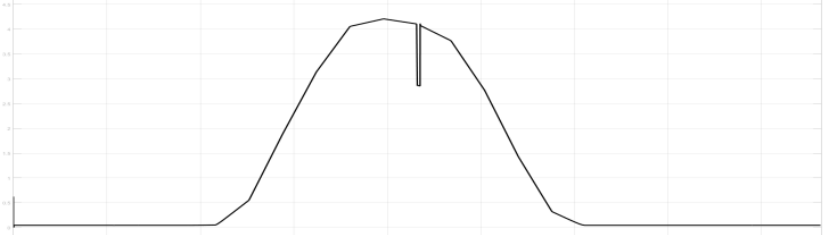

Fig. 16 Appararent Power (time vs reactive power)

\section{B. Load Consumption Details}

1) Residential Load

The load data is stored in the regulation data, based on these data the current, active, reactive power is varying as shown in the Fig.17- Fig.21

Fig. 17 Voltage Graph (time vs voltage) 


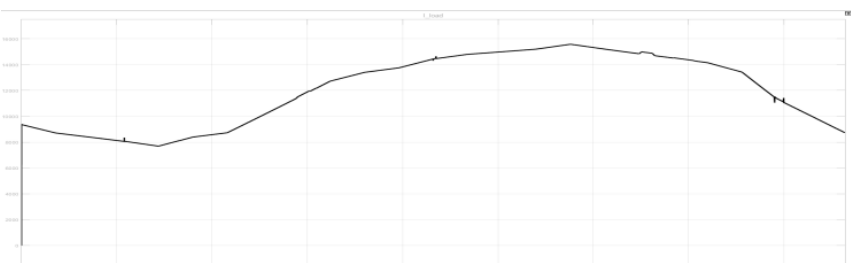

Fig. 18 Current Grpah (time vs current)

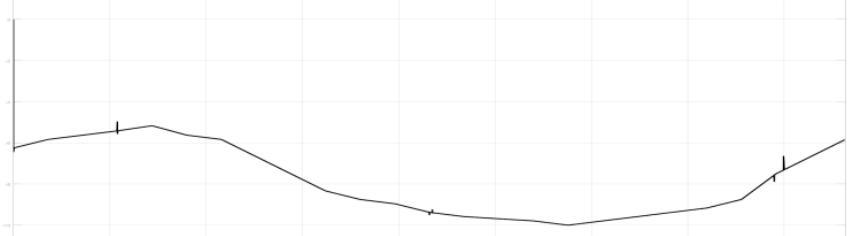

Fig. 19 Active Power (time vs active power)

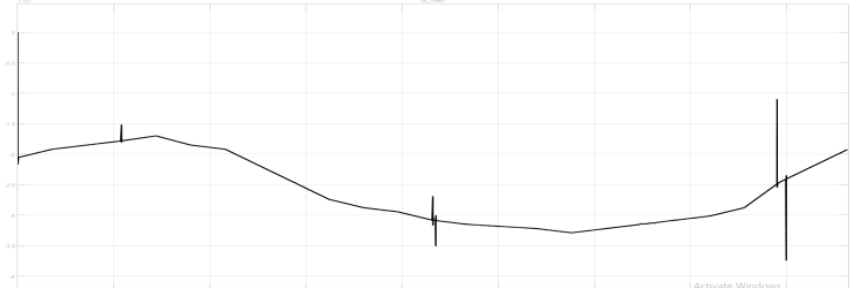

Fig. 20 Reactive Power (time vs reactine power)

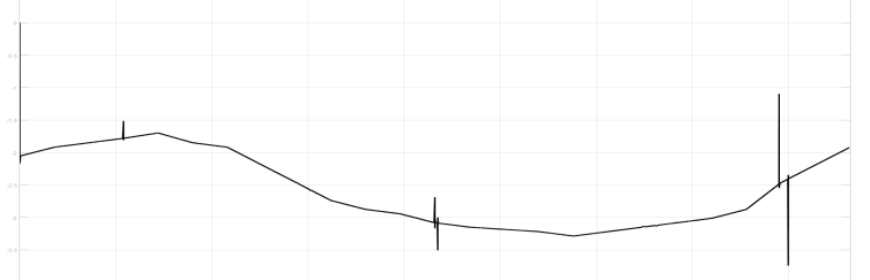

Fig. 21 Apparent Power (time vs reactive power)

1) Asynchronous Machine Inductive Load

Asynchronous Machine is a pure inductive type for simulating a small industrial load. The value is spiked at the start of the motor. The corresponding graphs of voltage, current and power is as shown in Fig. 22 - Fig. 26 respectively.

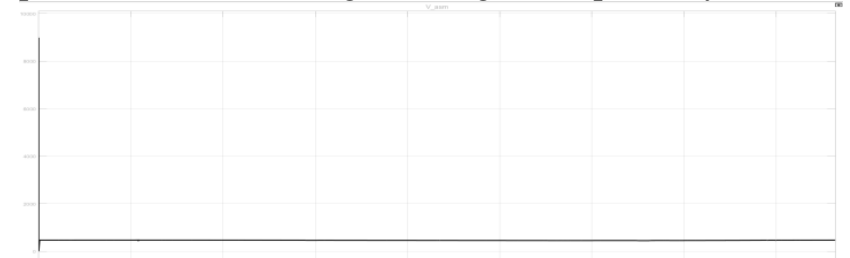

Fig. 22 Voltage Graph (time vs voltage)

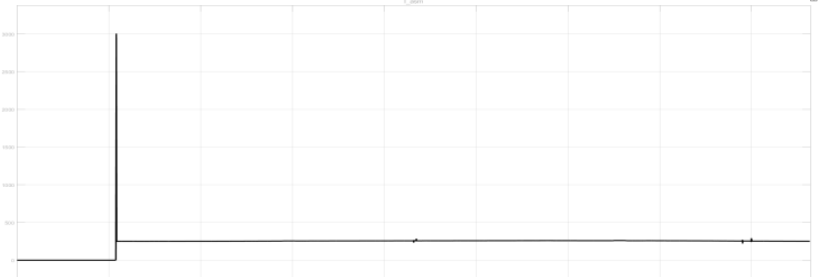

Fig. 23 Current Graph (time vs current)

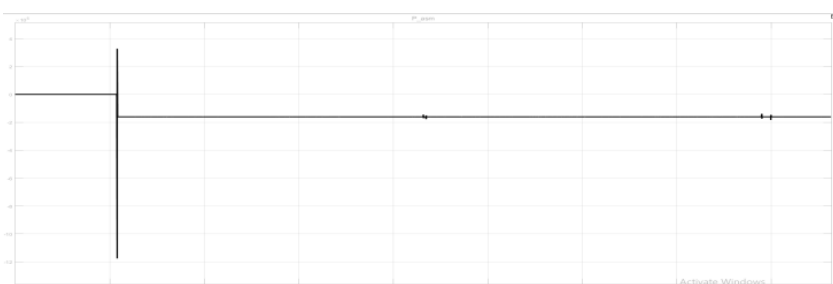

Fig. 24 Active Power (time vs active power)

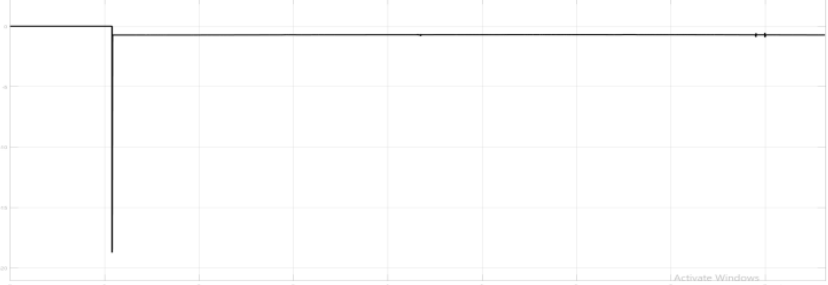

Fig. 25 Reactive Power (time vs reactine power)

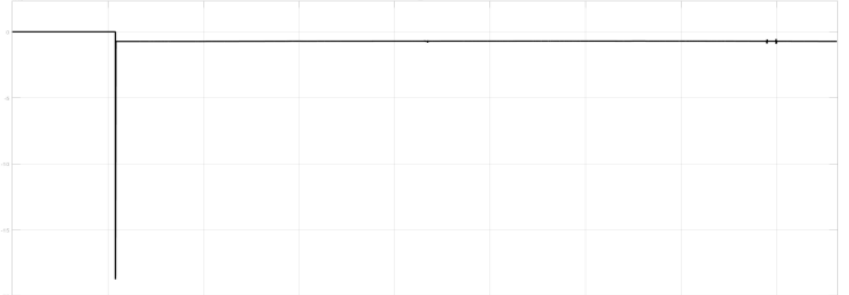

Fig. 26 Apparent Power (time vs reactive power)

\section{EV and Grid regulation Paramters}

1) Spikes in the grid Regulation

The rise in demand during peak load period is shown by spikes in current and active power otherwise it settles at the base and the small spike is due to the starting of the motor. The corresponding spikes in the residential load spikes are making it evident that the current requirement is increased so is the active and reactive power. The corresponding graphs are represent from Fig. 27 - Fig. 31.

Fig. 27 Voltage Graph (time vs voltage)

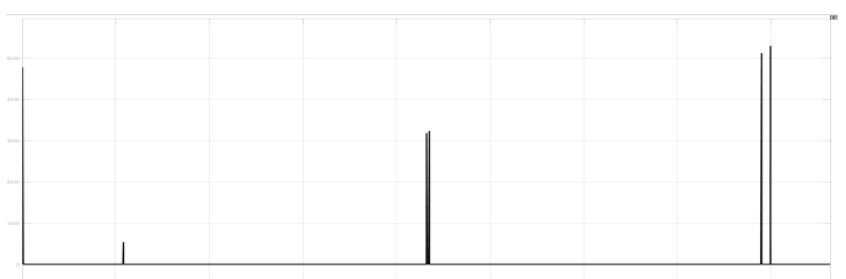

Fig. 28 Current Graph (time vs current) 
International Journal of Engineering Applied Sciences and Technology, 2020

Vol. 5, Issue 4, ISSN No. 2455-2143, Pages 203-208

Published Online August 2020 in IJEAST (http://www.ijeast.com)

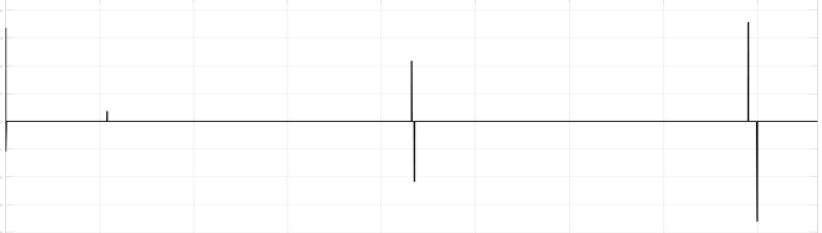

Fig. 29 Active Power (time vs active power)

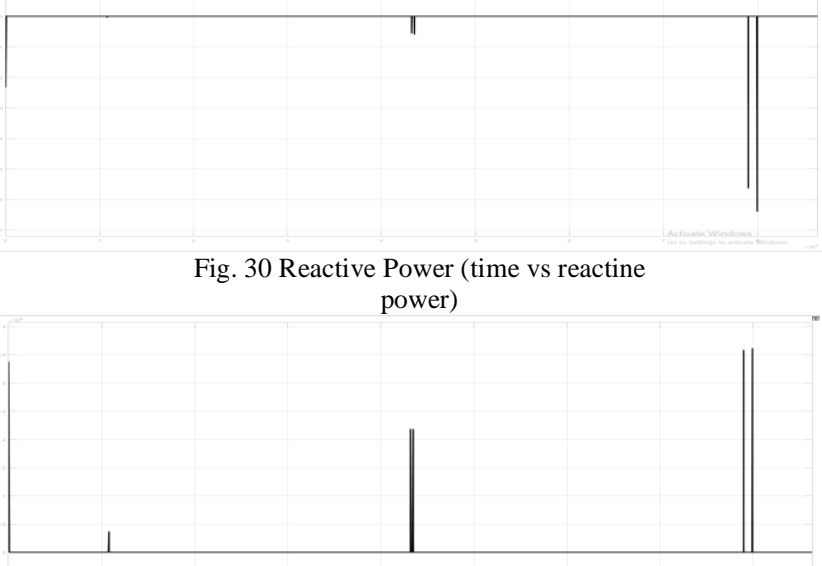

Fig. 31 Apparent Power (time vs reactive power)

2) Power Consumed by EVs for Charging

The graphs Fig.32-Fig.36 presents the voltage, current and the power level. The spikes represent the charging of the vehicle. Fig. 33 represent the current draw while charging of the Electric Vehicle. The noise present in the reactive power graph is due to the DC conversion.

Fig. 32 Voltage Graph (time vs voltage)

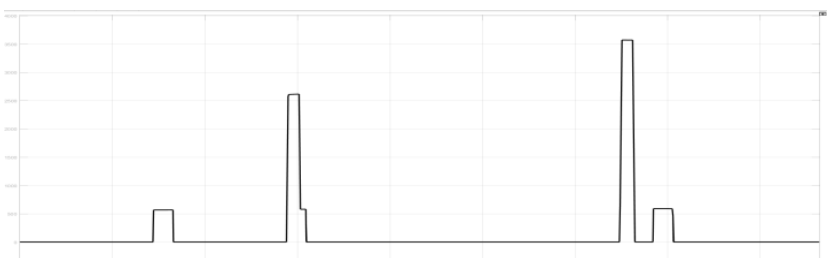

Fig. 33 Current Graph (time vs current)

Fig. 34 Active Power (time vs active power)

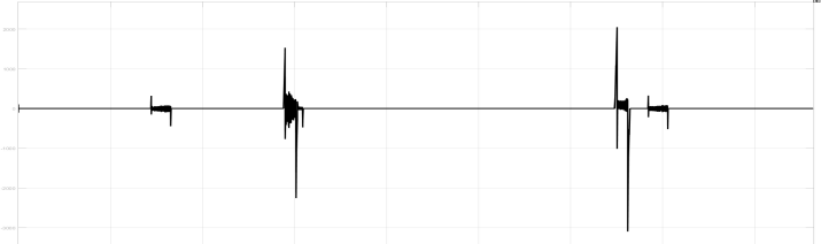

Fig. 35 Reactive Power (time vs reactine power)

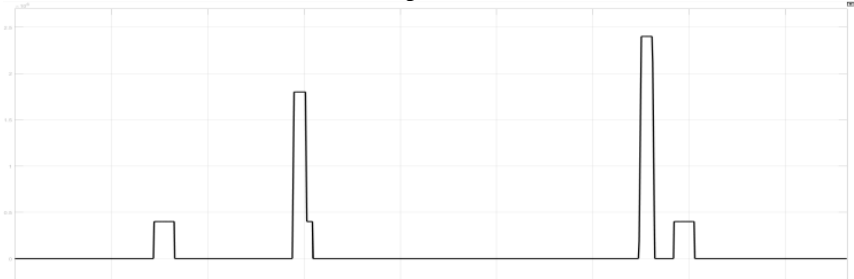

Fig.36 Apparent Power (time vs reactive power)

D. State of charge for different profile of Electric Vehicle

Based on the charging levels the graphs are as shown in Fig.37-Fig.41 during travelling and the availability of plug in for charging.

Profile 1: Possibility of people charging their car at work. The graph is as shown in Fig. 37

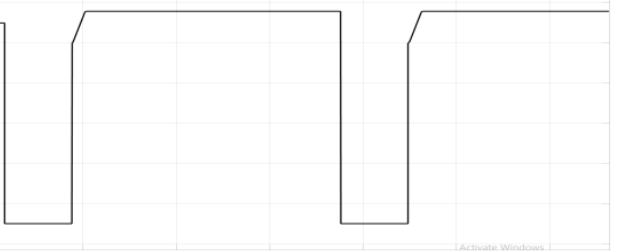

Fig. 37 Profile 1 (charging level vs time)

Profile 2: Possibility of charging the car at work but with a longer ride.

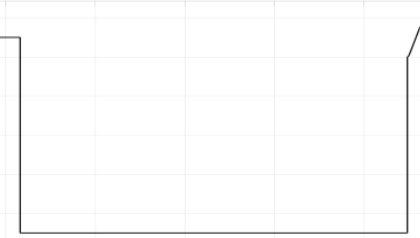

Fig. 38 Profile 2 (charging level vs time) 
Profile 3: Possibility of people going to work without charging their car at work.

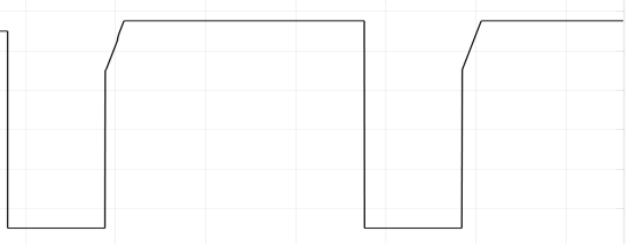

Fig. 39 Profile 3 (charging level vstime)

Profile 4: Possibility of people staying at home

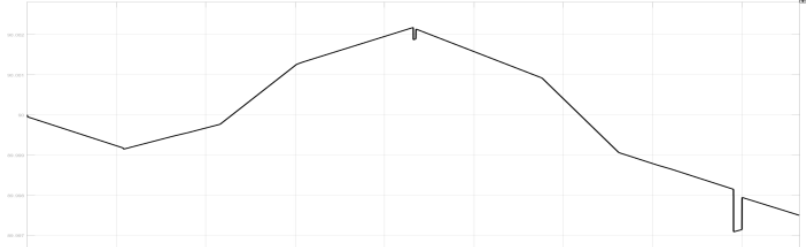

Fig. 40 Profile 4 (charging level vstime)

Profile 5:Possibility of people working on a night shift

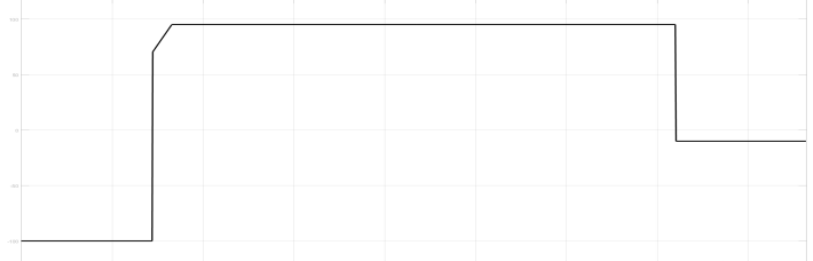

Fig. 41 Profile 5 (charging level vs time)

\section{CONCLUSION}

- A SIMULINK-MATLAB model is designed to understand the working of the Electric vehicle to Grid Technology using the renewable energy sources photo voltaic and wind and diesel power plant as base power plant.

- The Model presents a simplified Electric Vehicle to Grid Technology operation for load balancing and frequency regulation based on a power grid-integrated EV fleet.

- The solar intensity follows a normal distribution where it reaches the maximum intensity at midday. During the day the wind varies significantly and has many peaks and lows.

- The residential load follows a characteristic pattern that is similar to regular household usage. During the day, the consumption is low and rises to a peak value during the evening, and decreases slowly during the night.

- The simulation for five different scenarios dealing with the state of charge (i.e duration of the Electric vehicle getting charged and operated) of the electric vehicle is done.

\section{REFERENCES}

[1] Amamra Sid-Ali and Warwick Marco James.
(2019). Vehicle-to- Grid Aggregator to support power grid and reduce Electric Vehicle charging cost: A systematic Literature Review, IEEE Access.

[2] Liu Chunhua. Wu Diyun. and Gao Shuang. (2013). Opportunities and Challenges of Vehicle-to-Home, Vehicle-to-Vehicle, and Vehicle-to- Grid Technologies-Systematic Literature Review, Proceeding of IEEE.

[3] Haghbin Saeid. Lundmark Sonja. Alaküla Mats. and Carlson Ola. (2013). Grid-Connected Integrated Battery Chargers in Vehicle Application- Study on types of controllers.

[4] Mohamed Hassan Tarek. (2016). Load Frequency Control of an Isolated small Power System with Contribution of Vehicle-to-Grid V2G schemeApplication of standalone $\mathrm{V} 2 \mathrm{G}$ in isolated small areas, IEEE Conference.

[5] H.S.V.S Kumar Nunna. Battula Swathi. Doolla Suryanarayana and Srinivasan Dipti. (2016). Energy Management in Smart Distribution Systems with Vehicle-to-Grid Integrated Micro grids-Study of parameters involved in power distribution. IEEE Transaction on smart grid.

[6] Metin Kesler. C Mithat. Kisacikoglu. And Leon M Tolbert. (2013). Vehicle-to- Grid Reactive Power Operation Using Plug-In Electric Vehicle Bidirectional Off-Board Charger- Discussion of supply of reactive power from vehicle to the grid . IEEE Transactions on Industrial Electronics. DOI: 10.1109/TIE.2014.2314065.

[7] Gupta Madhuresh. Giri Soumyakanti. Dr. S Karthikeyan Prabhakar. (2018). Impact of Vehicle-toGrid on Voltage Stability - Indian Scenario. IEEE Conference.

[8] Toshihisa. (2016). Introduction, Integration of Distributed Energy Resources in Power Systems. Funabashi Institute of Materials and Systems for Sustainability (IMASS), Nagoya University, Nagoya, Japan. Elsevier.

[9] Yiyun Tu. Can Li. Lin Cheng. and Lin Le. (2011). Research on Vehicle-to- Grid Technology. IEEE Conference

[10] Tan Miao Kang. K Vigna. Ramachandaramurthy, Yong Ying Jia. (2016). Integration of electric vehicles in smart grids: A review on vehicle to grid technologies and optimization techniques. Elsevier. Volume 53, January.

[11] Wei-Hua Zhang. Nan Li. (2012). Study on the Wind and Solar hybrid control system: Study on power generation management in solar and wind hybrid plant . International Conference on Control Engineering and Communication Technology.

[12] S Ravikumar. Dr. Vennila H. (2017). Hybrid Wind solar system for efficient power generation. ICECA 2017.

[13] Gupta Priya. Sandhu K.S . (2019). Performance Analysis of Solar Panel under different operating conditions. ICECA 2019, IEEE Conference, ISBN: 978-1-7281-0167-5. 